\title{
Obstetrics and Gynecology Ultrasound and Evidence-based Medicine in Medical Education
}

${ }^{1}$ Lorenzo Aragon, ${ }^{2} \mathrm{Hoi}$ Ho

\begin{abstract}
Evidence-based medicine (EBM) is the conscientious, explicit and judicious use of current best evidence in making decisions about the care of individual patients. Despite improvement in knowledge, technology, effective medical therapies and ample practice guidelines, the practice of medicine in all specialties including obstetrics and gynecology (OB/GYN) continues to lag behind along with alarming rate of medical errors. Similarly, ultrasonography is rapidly expanding in the practice of medicine across many specialties but standardized requirements and ultrasound curricula for residency training in obstetrics and gynecology are still lacking.

EBM is a required component of the curriculum of medical education at all levels but still does not have a firm foothold in the practice of medicine in the United States and other countries because of barriers. There are many proposed changes to improve the efficacy of current teaching of EBM and ultrasound including an early introduction in preclinical curriculum and integration of a longitudinal EBM-ultrasound training in the continuum of medical education.

We present a case of postmenopausal bleeding (PMB) which was managed according to the traditional way, and review of EBM literature to contrast differences in clinical decision of two clinical approaches
\end{abstract}

Keywords: Ultrasonography, Ultrasound, Evidence-based medicine (EBM), Competency-based training, Preclinical curriculum, Medical education, Under graduate medical education, Postmenopausal bleeding (PMB).

How to cite this article: Aragon $\mathrm{L}, \mathrm{Ho} \mathrm{H}$. Obstetrics and Gynecology Ultrasound and Evidence-based Medicine in Medical Education. Donald School J Ultrasound Obstet Gynecol 2014;8(1):77-82.

Source of support: Nil

Conflict of interest: None

\section{INTRODUCTION}

Sir William Osler's time-tested statement 'The practice of medicine is an art, based on science. Medicine is a science of

\footnotetext{
${ }^{1}$ Associate Professor, ${ }^{2}$ Professor

${ }^{1}$ Department of Family and Community Medicine, Paul L Foster School of Medicine, Texas Tech University Health Sciences Center at EI Paso, Texas, USA

${ }^{2}$ Department of Internal Medicine; Associate Dean for Faculty Affairs and Development; Director, ATACS Center: Advanced Teaching and Assessment in Clinical Simulation, Paul L Foster School of Medicine, Texas Tech University Health Sciences Center at EI Paso, Texas, USA

Corresponding Author: Lorenzo Aragon, Associate Professor Department of Family and Community Medicine, Paul L Foster School of Medicine, Texas Tech University Health Sciences Center, 9849 Kenworthy St, EI Paso, TX 79924, USA e-mail: lorenzo.aragon@ttuhsc.edu
}

uncertainty and an art of probability' remains the cornerstone of teaching and practicing evidence-based medicine (EBM). ${ }^{1}$ The delivery of outstanding medical care requires providing care that is safe, effective, high quality, in the patient-best interest and affordable. Despite improvement in knowledge, technology and effective medical therapies, the practice of medicine in all specialties including obstetrics and gynecology continues to lag behind along with alarming rate of medical errors. ${ }^{2}$

At a crossroad, the US healthcare total cost was $\$ 2.1$ trillion in 2006, consuming $16 \%$ of gross domestic product (GDP). Unless EBM is effectively implemented into the healthcare system along with other measures, the national health spending is expected to reach $\$ 4.6$ trillion in 2020 . $^{3}$ Despite the integration of EBM into the curriculum of medical education at all levels, EBM still does not have a firm foothold in the practice of medicine in the United States and other countries because of many barriers. ${ }^{4,5}$ Effective practicing of EBM requires new skills that the healthcare providers need to acquire in early stage of medical education along with changes of the medical practice.

\section{A Paradigm Shift}

With massive technology evolution and rapid expansion of clinical research, EBM requires changes in medical practice that is profound enough to be called a paradigm shift. ${ }^{6}$ EBM de-emphasizes intuition, unsystematic clinical experience and pathophysiologic rationale as sufficient grounds for clinical decision making. Instead, it emphasizes the integration of best evidence from clinical research with the patient's values. ${ }^{6}$

\section{What is Evidence-based Medicine?}

EBM is the conscientious, explicit and judicious use of current best research evidence in making decisions about the care of individual patients. ${ }^{7}$ It is essential for the healthcare provider to be familiar with all five fundamental components of EBM for efficient integration of the best research evidence with the clinical expertise and patient values:

\section{Asking Focused and Answerable Question}

PICO (Patient, Intervention, Comparison, Outcome) is the most commonly used question format. ${ }^{8}$ There are PICO 
templates for individual category including treatment, prevention, diagnosis, prognosis, causation, patients' experiences and cost analysis. We recommend readers to visit and download useful templates at the Dartmouth website: http://www.dartmouth.edu/ library/biomed/guides/research/ ebm-resources-materials.html?mswitch-redir=classic.

\section{Finding the Best Research Evidence}

Obviously, finding the best evidence is the hardest part because it requires training, practice, resources and support (availability of computer, access to internet, Information Technology support). ${ }^{9}$ The librarians at academic institution are knowledgeable and helpful in assisting or training healthcare providers using available EBM resources. In addition, there are several excellent online resources for training EBM, such as Center for Evidence-based Medicine (http://www.cebm.net), or Evidence Based Medicine of British Medical Journal (http://ebm.bmj.com). The readers should also be familiar with different levels of evidence such as the Canadian Task Force on the Periodic Health Examination's Level of Evidence, the Oxford Centre for Evidence-Based Medicine (OCEBM) - Levels of Evidence (Table 1). The OCEBM levels have the advantage that they categorize levels of evidence according to therapy, prognosis, diagnosis, differential diagnosis and economic analysis in a single table (OCEBM Levels of Evidence Working Group*, Oxford Centre for Evidence-Based Medicine (http://www.cebm.net/index.aspx?o=5653). With proper software applications such as PubMed Tap, Bookends or Mendeley for mobile computing platform including iPad, Android-based tablets or smartphones, healthcare providers can easily access, search and retrieve best evidence.

\section{Critical Appraisal of Retrieved Research Evidences}

The readers should be able to use a systematic process to identify the strengths and weaknesses of the research study. Therefore, readers must have fundamental knowledge in biomedical statistics to appraise appropriately the retrieved literature. ${ }^{10}$ Center for Evidence Based Medicine, CEBM (http://www.cebm.net) is an excellent online resource for the readers to learn, practice critical appraisal and download free interactive applications and software such as CATmaker, a computer-assisted critical appraisal tool.

\section{Making a Decision}

In making a decision to treat the patient, provider must integrate the patient's values or preferences with results of best research evidence and clinical experience. This is the place and time that the providers demonstrate the 'art of medicine'. ${ }^{11}$ The single choice and paternalistic model of decision making of the traditional medicine should be replaced by multiple options that are patient-oriented, safe, effective and cost-efficient of the EBM approach. ${ }^{12,13}$

\section{Evaluating the Performance}

To continue enhancing the performance in using the other four steps of practicing EBM, the providers must frequently perform self-assessment of their efficiency and accuracy and patients' outcomes in practicing day to day EBM. ${ }^{14}$

\section{Barriers and Improvements of Teaching EBM in Undergraduate Medical Education}

Barriers exist in teaching, training, practicing and disseminating EBM. Most medical schools include EBM in their curricula but without standardized implementation. ${ }^{15,16}$ In a recent comprehensive literature review of EBM training in undergraduate medical education, Maggio et al have found several deficiencies in the current teaching strategies, such as knowledge gap and evaluation changes in practice. ${ }^{17}$ The authors also pointed out that all 20 reviewed literature sources lacked robust outcome measures to determine the efficacy of EBM integration in the curricula. The authors made several recommendations to improve the quality of teaching and training of EBM in undergraduate medical education (UGME): ${ }^{17}$

1. Timing of EBM instruction: early introduction of EBM in preclinical years.

2. Longitudinal EBM training: integration of an EBM spiral curriculum across preclinical and clinical years.

3. Interprofessional approach: Teaching EBM in an interprofessional education (IPE) environment to expand the students' exposure to professionals in other fields.

4. Active online learning: Use online teaching format to decompress classroom time, mitigate scheduling difficulties and promote a learner-oriented learning environment.

Table 1: Canadian task force on the periodic health examination's level of evidence*

\begin{tabular}{ll}
\hline Level & Type of evidence \\
\hline I & At least 1 randomized controlled trial (RCT) with proper randomization \\
II-1 & Well-designed cohort or case control study \\
II-2 & Time series comparisons or dramatic results from uncontrolled studies \\
III & Expert opinions
\end{tabular}

${ }^{*}$ Adapted from Canadian task force on the periodic health examination 
5. Gaps in knowledge: Provide tools and opportunities for learners to develop self-assessment of their EBM performance.

6. Electronic health records (EHRs): Use EHRs to expand the coverage of searching the biomedical literature.

\section{Barriers and Improvements of Teaching EBM in Graduate Medical Education}

The Accreditation Council for Graduate Medical Education (ACGME) mandates all residency and fellowship programs to provide opportunities for training and practicing EBM to the residents in all specialties (practice-based learning is one of the six ACGME core competencies). However, in reviewing published literature, Dijk et al found inconsistencies and identified several barriers in the implementation of EBM in graduate medical education (GME) (Table 2): ${ }^{4,5,18-20}$

1. Time: Limited time is the primary barrier and most frequently reported by the residents.

2. Attitude: Lack of personal initiative, motivation and/or interest.

3. Knowledge and skills: Lack of formal training in EBM and critical appraisal skills in addition to lack of basic computer skills.

4. Residency-related barriers: Lack of a favorable learning climate including faculty attitude toward EBM, faculty skills in EBM, institutional support for IT and resources can create negative influence on residents' motivation for practicing EBM.

\section{What to do When There is No Evidence or Clinicians do not know the Evidence?}

Sometimes the providers are faced with unique clinical problems but have no research evidences to support a clinical decision, despite extensive workup, literature search and consultation. This is the time that the providers will rely on an open and honest discussion with the patients and/or their family to inform them about the current medical situation and the limitation of the practitioners and medical literature as well as get their input in making an informed decision. ${ }^{11,13}$

\section{CASE EXAMPLE}

A 71 years old Hispanic female G4 P4, presented to a medical facility and complained of a new episode of vaginal serosanguinous discharge for the last 2 days. She described the vaginal discharge as mild brownish, small amount, non-foul smelling, without any associated pelvic pain, abdominal and/or urinary symptoms. She had her last menstrual period 20 years ago and denied any previous similar complaints. She had her last mammogram done 4 months ago and last Pap smear 6 years ago; both were normal. Past medical history is significant for well-controlled hypertension, diabetes mellitus (DM) type 2, obesity and hyperlipidemia. Family history is noncontributory. Patient is married, never smoked or drank alcohol. Review of systems was unremarkable except for the vaginal serosanguinous discharge.

\section{Physical Examination Revealed}

Height 62 inches, weight 193 pounds, BMI 35.43; temperature $98.5^{\circ} \mathrm{F}$; pulse rate 90 per minute; respiratory rate 18 per minute and blood pressure $147 / 76 \mathrm{~mm} \mathrm{Hg}$. Physical

Table 2: Barriers to practice of evidence-based medicine (adapted from the references ${ }^{4,5,18-20}$ )

\begin{tabular}{|c|c|c|}
\hline Parameters & Barriers to practice EBM & Measures to overcome challenges \\
\hline Time & Limited time for searching answers & $\begin{array}{l}\text { - Enhance performance through formal training in EBM } \\
\text { - Provide online EBM learning opportunities }\end{array}$ \\
\hline Attitude & Lack of motivation and interest & - Integrate EBM in curriculum \\
\hline Knowledge & Lack of formal training on EBM & $\begin{array}{l}\text { - Formal training of learners and trainers on EBM } \\
\text { - Introduce EBM in preclinical curriculum. Incorporate } \\
\text { formal training on EBM in GME }\end{array}$ \\
\hline Skills & Lack of training, practice and computer skills & $\begin{array}{l}\text { - Incorporate EBM in longitudinal training } \\
\text { - Promote the use of mobile computing platform } \\
\text { - Practice EBM on standardized patients (SPs) in clinical } \\
\text { simulation }\end{array}$ \\
\hline Learner-specific barriers & $\begin{array}{l}\text { Lack of faculty's approval and support for } \\
\text { EBM; language barrier }\end{array}$ & $\begin{array}{l}\text { - Incorporate EBM in faculty development curriculum } \\
\text { - Provide access to online resources }\end{array}$ \\
\hline Institutional resources & $\begin{array}{l}\text { Inadequate electronic information } \\
\text { technology and support }\end{array}$ & - Provide online access to EBM resources \\
\hline Practicing environment & $\begin{array}{l}\text { Inadequate electronic information } \\
\text { technology }\end{array}$ & - Provide online access to EBM resources \\
\hline Local expertise in EBM & Lack of help in interpretation by experts & $\begin{array}{l}\text { - Development program for champions at local institution } \\
\text { - Develop networking with EBM-established institutions }\end{array}$ \\
\hline Patients-specific barriers & Patients' preference or demand & $\begin{array}{l}\text { - Improve patient education } \\
\text { - Educate the public and media on EBM }\end{array}$ \\
\hline
\end{tabular}


examination of the heart, lungs and abdomen were normal. With the exception of a small, non-foul smelling vaginal brownish discharge, the examination of the pelvic, external genitalia, urethral meatus, vagina and cervix were normal, without adnexal mass or tenderness. Result of Pap smear was negative for intraepithelial lesion of malignancy. Patient was sent home with a follow-up in 5 months.

Patient returned 5 months later for follow-up of her DM and still complained of bloody vaginal discharge and mild back pain. During the visit, a transvaginal pelvic ultrasound showed a normal shape anteverted uterus with a diffuse mass-like thickening of the entire endometrium extending up to the internal os. The endometrium was ill defined, predominantly hyperechoic and measured $2.2 \mathrm{~cm}$ in anteroposterior diameter (Fig. 1). There was evidence of multiple cystic inclusions measuring from 1 to $3 \mathrm{~mm}$. Color Doppler revealed intense vascularity (Fig. 2). Ultrasound findings were suggestive of endometrial malignancy. The patient was referred to gynecology service for endometrial biopsy. In view of diffuse endometrial hyperplasia with atypia, patient underwent total abdominal hysterectomy. The final pathology report was endometrial adenocarcinoma. Endometrial carcinoma is a highly curable and treatable cancer when diagnosed in its early stage. It occurs most commonly in the 6 th and 7 th decades with a 5 years survival rate close to $65 \% .^{21}$ The most common presenting symptoms, occurring in about $90 \%$ of patients is abnormal vaginal bleeding. Before 1980s, dilation and curettage (DandC) was commonly used for diagnosis. Today transvaginal ultrasound, saline infusion sonography (SIS), endometrial biopsy (EMB) and hysteroscopy are available effective diagnostic procedures. Endometrial thickness of more than 5 $\mathrm{mm}$ is considered a highly sensitive parameter for follow-up biopsy of abnormally thickened endometrium. When using endometrial thickness of $\geq 4 \mathrm{~mm}$ as sonographic cut-off to exclude the endometrial malignancy, the sensitivity and specificity of ultrasound were 92.9 and $100 \%$ respectively. ${ }^{21}$

\section{What happens if EBM Approach is used in Management of This Case?}

Uterine cancer is the most common gynecologic malignancy in the Unites States and other developed countries. Up to $25 \%$ of women with postmenopausal bleeding will be diagnosed with endometrial malignancy. ${ }^{21,22}$ The main risk factor for endometrial malignancy is long-term exposure to excess endogenous or exogenous estrogen. Other identified risk factors include obesity, diabetes mellitus, increasing age, nulliparity and hypertension. ${ }^{22}$ Since this patient has multiple risk factors for developing endometrial malignancy, the provider can easily use one of the predictive models such

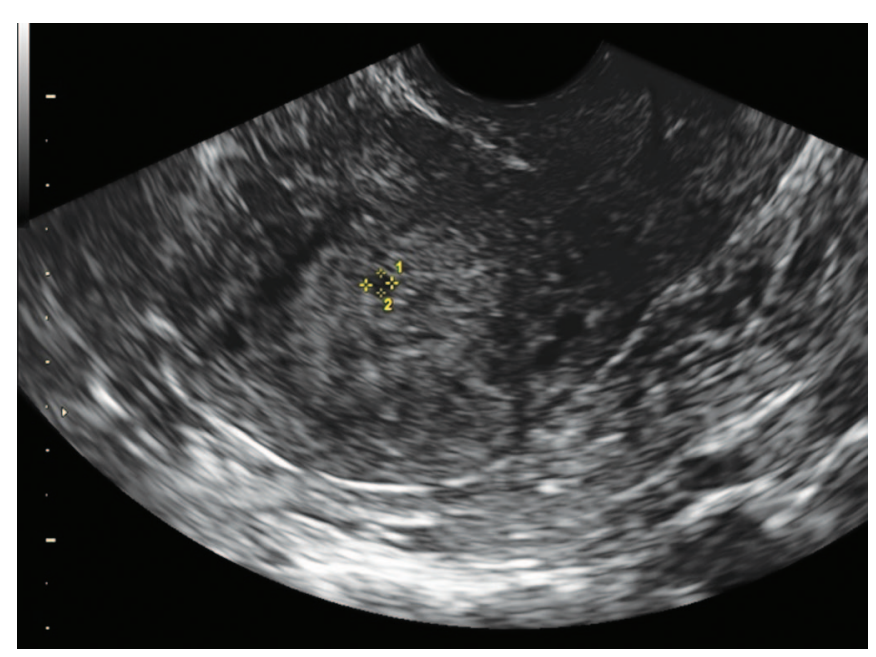

Fig. 1: Abnormally thickened endometrium (22 mm). Note multiple cystic inclusions measuring 1 to $3 \mathrm{~mm}$

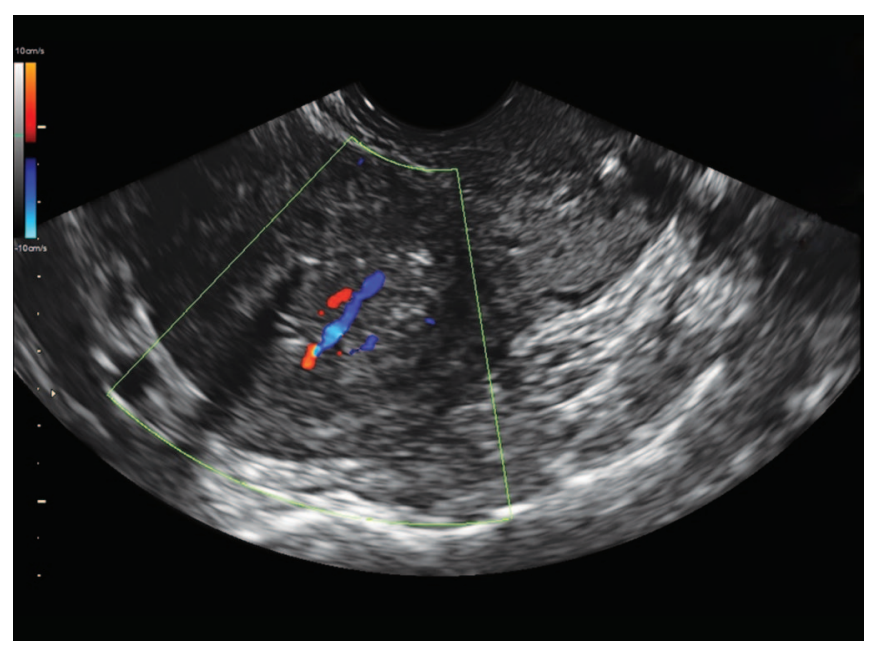

Fig. 2: Color Doppler reveals increased vascularity at the periphery of abnormally thickened endometrium

as the DFAB (D stands for diabetes mellitus, F for frequency of bleeding episodes, A for age, and B for BMI cut off value of 31$)^{23,24}$ to estimate the risk of endometrial cancer (Table 3). DFAB score $\geq 4$ has a sensitivity of $81.8 \%$ and specificity of $50.8 \%$ in detecting endometrial malignancy. Since our patient has a DFAB $\geq 4$, she should have been referred to further diagnostic procedures such as transvaginal ultrasound, SIS, endometrial biopsy or hysteroscopy during the initial visit and not 5 months later.

Therefore, how should we evaluate the patient presenting with PMB? Should we start with transvaginal ultrasound or EMB in the office? Other causes of bleeding, such as polyps, hyperplastic endometrium, atrophic endometrium or fibroids also need to be considered in differential diagnosis. Expert panels have recommended transvaginal ultrasound or EMB as the first step in the assessment of postmenopausal bleeding. If patient has high risk of endometrial adenocarcinoma, such as in our case, EMB may be the first choice for evaluation. The sonogram will be interpreted as abnormal if the 
Table 3: Predictive model DFAB in estimating risk of endometrial malignancy

\begin{tabular}{llll}
\hline Risk factor $(R F)$ & Value with RF & Value without RF & Patient DFAB \\
\hline Diabetes mellitus & 2 & 0 & 2 \\
$\begin{array}{l}\text { Frequency of } \\
\text { bleeding }\end{array}$ & 4 & 0 & $?$ \\
Age $\geq 64$ & 1 & 0 & 1 \\
BMI $\geq 31$ & 1 & 0 & 1 \\
\hline Total score & & & $\geq 4$
\end{tabular}

double thickness of endometrium is greater than $5 \mathrm{~mm}$. The sonogram will be nondiagnostic if the endometrium cannot be visualized entirely. SIS or hysteroscopy will be recommended when focal abnormality is anticipated on transvaginal sonography. SIS does not require anesthesia and can be done as office procedure. The accuracy of SIS and diagnostic hysteroscopy are similar. If SIS shows diffuse endometrial thickness, the next step should be EMB.

\section{CONCLUSION}

Despite the integration of EBM into the curriculum of medical education at all levels, the teaching and practice of EBM still lag behind improvement in research evidences, technology and medical therapies because of the barriers in medical education, working environment and/or maldistribution of resources. Bridging the barriers of EBM in medical education will require systematic reform of the curriculum and training in EBM at all levels, in addition to adequate resources and support for technology.

\section{REFERENCES}

1. Osler William, Silverman Mark E, Murray TJ, Bryan Charles S (2002). The Quotable Osler. Philadelphia: HYPERLINK “http:// en.wikipedia.org/wiki/American_College_of_Physicians"’o "American College of Physicians" American College of Physicians. HYPERLINK "http://en.wikipedia.org/wiki/International_ Standard_Book_Number" \o "International Standard Book Number" ISBN HYPERLINK "http://en.wikipedia.org/wiki/ Special:BookSources/978-1-930513-34-1" \o "Special:BookS ources/978-1-930513-34-1" 978-1-930513-34-1. HYPERLINK "http://en.wikipedia.org/wiki/OCLC" \o "OCLC" OCLC HYPERLINK "http://www.worldcat.org/oclc/50477294" 5047729 .

2. Medicine Io. Crossing the Quality Chasm: a new health system for the 21st Century. Washington DC: National Academy Press; 2001.

3. National Health Expenditure Projection 2010-2020. 2010. at https://www.cms.gov/Research-Statistics-Data-and.../proj2010 pdf).

4. van Dijk N, Hooft L, Wieringa-de Waard M. What are the barriers to residents' practicing evidence-based medicine? A systematic review. Academic Medicine. Journal of the Association of American Medical Colleges 2010;85:1163-1170.

5. Haynes B, Haines A. Barriers and bridges to evidence based clinical practice. BMJ 1998;317:273-276.
6. Guyatt G, Cairns J, Churchill D, Cook D, Haynes B, Hirsch J, Sackett D, et al. Evidence-based medicine. A new approach to teaching the practice of medicine. Evidence-based medicine working group. JAMA 1992;268(17):2420-2425.

7. Sackett DL, Rosenberg WM, Gray JA, Haynes RB, Richardson WS. Evidence based medicine: what it is and what it is not. BMJ 1996;312:71-72.

8. Sackett DL, Straus SE, Richardson WS, Rosenberg W, Haynes RB. In: Evidence-Based Medicine: How to Practice and Teach EBM. 2nd ed. Edinburgh, Scotland: Churchill Livingstone; 2000; p. 2-3, 87.

9. Rosenberg WM, Deeks J, Lusher A, Snowball R, Dooley G, Sackett D. Improving searching skills and evidence retrieval. Journal of the Royal College of Physicians of London 1998;32:557-563.

10. Young JM, Solomon MJ. How to critically appraise an article. Nature-Clinical Practice 2009;6:82-91.

11. O'connor A. Using patient decision aids to promote evidencebased decision making. Evid Based Med BMJ 2001;6:100-102.

12. Strull WM, Lo B, Charles G. Do patients wants to participate in medical decision making? JAMA 1984;252:2990-2994.

13. Emanuel EJ, Emanuel LL. Four models of the physician-patient relationship. JAMA 1992;267:2221-2226.

14. Feldstein DA, Vogelman BS. Teaching and evaluating evidence-based medicine competency using a web-based educational prescription. Academic Internal Medicine Insight.2012;10(2):6-8. http://www.im.org/Publications/Insight/ Archives/2012/v10i2/Pages/Article3.aspx.

15. Lai NM, Teng CL. Self-perceived competence correlates poorly with objectively measured competence in evidence based medicine among medical students. BMC Medical Education 2011;11:25.

16. Tilson JK, Kaplan SL, Harris JL, et al. Sicily statement on classification and development of evidence-based practice learning assessment tools. BMC Medical Education 2011;11:78.

17. Maggio LA, Tannery NH, Chen HC, ten Cate O, O'Brien B. Evidence-based medicine training in undergraduate medical education: a review and critique of the literature published 2006-2011. Academic Medicine: Journal of the Association of American Medical Colleges 2013;88:1022-1028.

18. Zwolsman S, Te Pas E, Hooft L, Wieringa-de Waard M, van Dijk N. Barriers to GPs' use of evidence-based medicine: a systematic review. The British Journal of General Practice: Journal of the Royal College of General Practitioners 2012; 62:e511-521.

19. Risahmawati RR, Emura SS, Nishi TT, Koizumi SS. Japanese Resident Physicians' Attitudes, knowledge, and Perceived Barriers on the Practice of Evidence Based Medicine: a Survey. BMC Research Notes 2011;4:374. 
20. Poses RM. Money and mission? Addressing the barriers to evidence-based medicine. Journal of General Internal Medicine 1999;14:262-264.

21. Bakour SH, Dwarakanath LS, Khan KS. The diagnostic accuracy of ultrasound scanin predicting endometrial hyperplasia and cancer in postmenopausal bleeding. Acta Obstet Gynecol Scand 1999;78:447-451.

22. Alberico S, Conoscenti G, Veglio P, Bogatti P, Di Bonito L, Mandruzzato G. A clinical and epidemiological study of 245 postmenopausal metrorrhagia patients. Clinical and Experimental Obstetrics and Gynecology 1989;16:113-121.
23. Burbos N, Musonda P, Duncan TJ, Crocker SG, Morris EP, Nieto JJ. Estimating the risk of endometrial cancer in symptomatic postmenopausal women: a novel clinical prediction model based on patients' characteristics. International journal of gynecological cancer: Official Journal of the International Gynecological Cancer Society 2011;21:500-506.

24. Musonda P, Burbos N, Duncan TJ, Crocker SG, Morris EP, Nieto JJ. Comparing the performance of two clinical models in estimating the risk of endometrial cancer in symptomatic postmenopausal women. European Journal of Obstetrics, Gynecology, and Reproductive Biology 2011;159:433-438. 